\title{
Habitual high phosphorus intakes and foods with phosphate additives negatively affect serum parathyroid hormone concentration: a cross-sectional study on healthy premenopausal women
}

\author{
Virpi E Kemi ${ }^{1}$, Hannu J Rita ${ }^{2}$, Merja UM Kärkkäinen ${ }^{1}$, Heli T Viljakainen ${ }^{1}$, \\ Marika M Laaksonen ${ }^{1}$, Terhi A Outila ${ }^{1}$ and Christel JE Lamberg-Allardt ${ }^{1, *}$ \\ ${ }^{1}$ Calcium Research Unit, Department of Applied Chemistry and Microbiology, PO Box 66, FIN-00014, \\ University of Helsinki, Finland: ${ }^{2}$ Faculty of Agriculture and Forestry, University of Helsinki, Helsinki, Finland
}

Submitted 21 January 2008: Accepted 7 December 2008: First published online 16 February 2009

\begin{abstract}
Objective: Foods can contain natural phosphorus (NP) and phosphate-containing food additives (AP). The main objective of the present study was to investigate whether NP and AP of habitual diets differ in their effects on markers of Ca metabolism. We also investigated the impact of total habitual dietary $\mathrm{P}$ intake on markers of Ca metabolism.

Design: Cross-sectional study. Fasting blood samples were collected and participants kept a $4 \mathrm{~d}$ food record, from which dietary intake of total $\mathrm{P}$ and the consumption of NP (milk and cheese, excluding processed cheese) and AP (processed cheese) sources were calculated. Participants were divided into groups according to their $\mathrm{NP}$ - and AP-containing food consumption and into quartiles according to their total $\mathrm{P}$ intake.

Setting: Southern Finland.

Subjects: One hundred and forty-seven healthy premenopausal women aged 31-43 years.

Results: Relative to the lowest total dietary $\mathrm{P}$ quartile, mean serum parathyroid hormone (S-PTH) concentration was higher $(P=0 \cdot 048$, analysis of covariance (ANCOVA) ) and the mean serum ionized $\mathrm{Ca}$ concentration lower $(P=0 \cdot 016$, ANCOVA) in the highest $\mathrm{P}$ intake quartile. Mean S-PTH concentrations were higher among participants who consumed processed cheese $(P=0 \cdot 027$, ANCOVA $)$ and less milk and other cheese than processed cheese $(P=0 \cdot 030$, ANCOVA).

Conclusions: High total habitual dietary P intake affected S-PTH unfavourably. Furthermore, phosphate additives may have more harmful effects on bone than other P sources, as indicated by higher mean S-PTH concentration among participants who consumed AP-containing foods. Because of the high dietary P intake and current upward trend in consumption of processed foods in Western countries, these findings may have important public health implications.
\end{abstract}

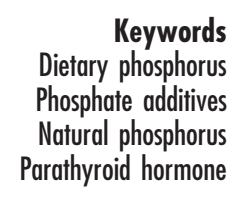

P unlike $\mathrm{Ca}$ is abundant in many food sources, as foods can contain both natural $\mathrm{P}$ and phosphate-containing food additives. In many countries, $\mathrm{P}$ intake is two- to threefold higher ${ }^{(1-4)}$ than the dietary reference intake for $\mathrm{P}(700 \mathrm{mg} / \mathrm{d})^{(5)}$, while Ca intake is often below recommended levels ${ }^{(6-9)}$. Such a combination, or even a high $\mathrm{P}$ intake alone, may be harmful to bone through increased parathyroid hormone (PTH) secretion ${ }^{(10-13)}$.

$\mathrm{PTH}$ is a major regulator of $\mathrm{Ca}$ and bone metabolism, and continuous excessive PTH secretion increases bone turnover ${ }^{(14,15)}$. Dietary $\mathrm{P}$ has been found to increase serum PTH (S-PTH) concentration by decreasing serum ionized
$\mathrm{Ca}$ (S-iCa) concentration ${ }^{(16)}$ and by directly affecting PTH secretion ${ }^{(17)}$, probably through the Na-dependent phosphate co-transporter in the parathyroid glands ${ }^{(18)}$. In contrast to continuous excessive PTH secretion, intermittent administration of PTH stimulates bone formation ${ }^{(19)}$ and increases trabecular bone mass ${ }^{(20)}$. Therefore, in vivo, the combined effect of P and PTH on bone metabolism is complex and may vary from an acute situation to a long-term one.

$\mathrm{P}$ sources may differ in their effects on $\mathrm{Ca}$ and bone metabolism; a recent short-term controlled study revealed that $\mathrm{P}$ originating from phosphate additives alone 
increased S-PTH concentration more than P from cheese, meat and wholegrain products ${ }^{(21)}$. Intestinal absorption of $\mathrm{P}$ is efficient and absorption occurs by both passive and active transport, the latter being stimulated by 1,25-dihydroxyvitamin $\mathrm{D}^{(22)}$. The absorbability of $\mathrm{P}$ in Ca-containing dairy products is not well known; however, in renal disease Ca compounds are used to bind dietary $\mathrm{P}^{(23)}$. In plants, much of the $\mathrm{P}$ is in the form of phytate, which is poorly digested. Less $\mathrm{P}$ is therefore absorbed unless the food is supplemented with the enzyme phytase, e.g. by leavening bread with yeast producing phytase ${ }^{(24)}$. In addition, $\mathrm{P}$ in the form of phosphate additives in processed foods has been suggested to be almost completely absorbed ${ }^{(24)}$.

Phosphate additives are commonly used in the food industry. The amounts used are generally below the recommended limits ${ }^{(25)}$; however, some products, e.g. low-fat processed cheeses, may contain nearly the maximum allowable amount of phosphate additives ${ }^{(26)}$. In Finland, other important sources of phosphate additives are confectioneries leavened with baking powder, plant extract drinks, sausages and other meat products, and most processed foods ${ }^{(26)}$. Nevertheless, accurate estimation of the intake of $\mathrm{P}$ from food additives is difficult, as the amounts of phosphate additives used in industrially prepared foods are not well known ${ }^{(26,27)}$.

Earlier epidemiological studies have revealed unfavourable effects of phosphoric acid-containing soft drinks on bone ${ }^{(28-30)}$. However, few studies exist regarding the effects of other foods containing phosphate additives on $\mathrm{Ca}$ and bone metabolism, although soft drinks are not the main sources of phosphate additives at the population level. In the present cross-sectional study, our objective was to compare the effects of dietary P originating from natural $\mathrm{P}$ (NP) with that originating from phosphate additives (AP) on $\mathrm{Ca}$ and bone metabolism. We hypothesized that dietary $\mathrm{P}$ from $\mathrm{AP}$ would have a more deleterious impact on $\mathrm{Ca}$ and bone metabolism than dietary NP. Our earlier controlled short-term studies ${ }^{(12,13)}$ established that high total dietary $\mathrm{P}$ intake has negative effects on $\mathrm{Ca}$ and bone metabolism. Our further objective was to investigate whether the same effects of total high dietary P intake could also be seen in the habitual diets of healthy individuals. We hypothesized that high total dietary $\mathrm{P}$ intake would have a more unfavourable impact than low intake on $\mathrm{Ca}$ and bone metabolism.

\section{Participants and methods}

\section{Participants}

Our data form part of a cross-sectional study conducted in southern Finland from February to March 1998. Our participants represent a randomly selected subgroup of 31- to 43-year-old Finnish women. Details about participants have been provided elsewhere ${ }^{(31)}$. Only women with no illnesses or medications affecting Ca metabolism were included. Women with no or irregular menstruation as well as those with incomplete $4 \mathrm{~d}$ food records were excluded. Our final study group comprised 147 healthy premenopausal women. Power calculation based on S-PTH concentration (expected difference between groups in mean S-PTH concentration of $12 \mathrm{ng} / \mathrm{l}$ ), assuming $90 \%$ power with $\alpha=0 \cdot 05$, showed that a sample size of eleven in each group was adequate. In 1998, before the study, each participant gave her informed consent to the procedures, which were conducted in accordance with the Helsinki Declaration. The Helsinki University Ethics Committee approved the study protocol.

\section{Questionnaire and information collection}

A questionnaire was used to collect information on weight, height, physical activity, smoking habits and alcohol consumption of participants during the last two weeks in February or March 1998. In addition, the questionnaire requested information on age, age at menarche, past medical history, menstruation cycle, use of supplements and lactose intolerance.

\section{Nutritional assessment}

To gather data on habitual energy and nutrient intakes, participants were instructed on how to keep a $4 \mathrm{~d}$ food record, which included three weekdays and one day of the weekend. Participants were advised to maintain their habitual food intakes during this period and to record all foods and beverages immediately after consumption. A nutritionist together with the participant checked the $4 \mathrm{~d}$ food record. We calculated participants' habitual dietary intakes with a computer-based program, the Unilever Dietary Analysis Program (UNIDAP; Becel Palvelu Paasivaara Oy, Finland, 1989), based on the food composition database (Fineli) of the Finnish National Public Health Institute. Nutrient contents of all foods here are based on the food composition database (Fineli) of the Finnish National Public Health Institute ${ }^{(32)}$.

\section{Study design}

To examine the effects of different sources of dietary $\mathrm{P}$, we divided participants into groups based on the information provided in their $4 \mathrm{~d}$ food records. Group characteristics and their sizes are presented in Table 1. For total $\mathrm{P}$ intake we used quartiles. To test our hypothesis, we chose to investigate only the extreme total $\mathrm{P}$ quartiles and ignored the quartiles situated between them. This allowed us to study the total $\mathrm{P}$ intakes in a manner similar to our earlier controlled study designs ${ }^{(12,13)}$. Dairy products are the main $\mathrm{P}$ sources in the Finnish diet $^{(3)}$, with milk and cheese, excluding processed cheese, representing commonly consumed dairy products containing only NP. Due to skewed distribution of $\mathrm{P}$ in milk and cheese, participants were divided into two groups of equal size (low and high consumption) according to their median $\mathrm{P}$ intake. As processed cheese contains AP, it was 
Table 1 Quartiles and groups studied

\begin{tabular}{|c|c|c|c|}
\hline \multirow[b]{2}{*}{ Quartiles and groups } & \multicolumn{2}{|c|}{$P$ intake (mg/d) } & \multirow[b]{2}{*}{ No. of subjects } \\
\hline & Mean & SE & \\
\hline \multicolumn{4}{|l|}{ Total P intake } \\
\hline 1st quartile & 961 & 22 & 37 \\
\hline 4th quartile & 1956 & 48 & 35 \\
\hline \multicolumn{4}{|l|}{ Milk and cheese* } \\
\hline Low consumption & $244 \dagger$ & 12 & 74 \\
\hline High consumption & $588+$ & 25 & 73 \\
\hline \multicolumn{4}{|l|}{ Processed cheese } \\
\hline Non-consumers & 0 & - & 110 \\
\hline Consumers & $240 \ddagger$ & 34 & 37 \\
\hline
\end{tabular}

*Two groups of equal size (low and high consumption) according to the median intake of $\mathrm{P}$ from milk and cheese, excluding processed cheese (374 mg/d).

†P intake from milk and cheese, excluding processed cheese.

$\ddagger P$ intake from processed cheese.

examined separately from milk and other cheese than processed cheese. The small number of consumers of processed cheese forced us to use division into two groups of unequal size (consumers and non-consumers).

\section{Sampling}

On study days, blood samples were taken anaerobically between 07.30 and 09.15 hours after a $12 \mathrm{~h}$ overnight fast. The separated serum samples were stored at $-20^{\circ} \mathrm{C}$ until analysed.

\section{Laboratory measurements}

The S-iCa concentration was analysed within $90 \mathrm{~min}$ of sample collection with an ion-selective analyser (Microlyte 6; Thermo Electron Corp., Vantaa, Finland). The intra-assay CV was $1.6 \%$ for S-iCa. The serum intact PTH (S-iPTH) concentration was measured using an immunoradiometric assay (Nichols Institute, Juan San Capistrano, CA, USA) with 10-65 ng/l as a reference range. Intra- and inter-assay CV for $\mathrm{S}$-iPTH were $3 \cdot 7 \%$ and $1.0 \%$, respectively. Serum 25-hydroxyvitamin D (S-25(OH)D) concentration was measured by RIA (Incstar Corp., Stillwater, MN, USA). The intraand inter-assay CV were $10 \cdot 1 \%$ and $14 \cdot 9 \%$, respectively.

\section{Statistical analysis}

Hypothesis and statistical approaches

Our data analysis was tailored to test the hypothesis 'Dietary AP affects bone metabolism more harmfully than dietary NP'. First, we estimated the effect of dietary AP by comparing means of S-PTH among consumers and nonconsumers of processed cheese. Next, potential distortions of these averages were removed by adjusting them for the effects of relevant covariates. The choice of these covariates is discussed in the next paragraph. Finally, the two averages were adjusted for total $\mathrm{P}$ intake to exclude the effect of increased total $\mathrm{P}$ intake due to consumed processed cheese. The critical point with respect to testing our hypothesis is whether the difference between the consumer groups prevails even after this adjustment; if so, our hypothesis gains support. With this same technique, we estimated the effect of dietary NP by comparing the averages of S-PTH among low and high milk and cheese (excluding processed cheese) consumption groups. The statistical approach originates from an elaboration technique $^{(33)}$, but we have used it in a more confirmatory spirit like e.g. Penttilä et al. ${ }^{(34)}$ and Sah et al. ${ }^{(35)}$. We also tested the hypothesis 'High total dietary $\mathrm{P}$ intake affects bone metabolism more harmfully than low intake' by comparing averages of S-PTH in the first and fourth total $\mathrm{P}$ intake quartiles after adjusting for all relevant covariates. As S-iCa is a central factor in $\mathrm{Ca}$ and bone metabolism, we studied the effects of AP, NP and total P intake on $\mathrm{S}$-iCa as well. Our technical tool for all data analysis was analysis of covariance (ANCOVA) because it enables inclusion of both categorical (e.g. use of contraceptives) and continuous (e.g. S-iCa) explanatory variables. We used the SPSS statistical software package version 12.07 (SPSS Inc., Chicago, IL, USA, 2003) in a Windows environment for all statistical analyses. Results were considered statistically significant at $P<0 \cdot 05$. Data are presented as means with their standard errors.

\section{Covariates}

Several factors are known to affect S-PTH concentration, which we use as a measure of $\mathrm{Ca}$ and bone metabolism. Among these are nutrient intakes ( $\mathrm{Ca}, \mathrm{P}$ and $\mathrm{Na}$ ) and serum variables $(\mathrm{S}-25(\mathrm{OH}) \mathrm{D}$ and $\mathrm{S}-\mathrm{iCa})$. The use of contraceptives might also affect S-PTH ${ }^{(36)}$. When the means of S-iCa were compared, S-PTH was included in and $\mathrm{Na}$ intake excluded from covariates. We excluded age from the covariates, as all participants represented the same age group and all were premenopausal women. Energy intake was also excluded from the covariates because $\mathrm{Ca}$ and $\mathrm{P}$ intakes correlated well with energy intake. Furthermore, body weight had no effects on the variables measured, and thus was not included in the covariates. In summary, we chose covariates that correlated with the outcome parameter or covariates known to affect the outcome according to the literature.

\section{Results}

\section{Baseline characteristics}

The baseline characteristics of the 147 participants are presented in Table 2. Of all participants, thirty-nine (27\%) used contraceptives. The average dietary intake of $\mathrm{P}$ and $\mathrm{Ca}$ of participants (Table 2) corresponds to the average intake of $\mathrm{P}$ and $\mathrm{Ca}$ in Finnish females ${ }^{(3)}$.

\section{Effect of total dietary $P$ intake on serum paratbyroid bormone}

The mean S-PTH concentration of participants was $30 \cdot 6$ (SE 1.3) ng/l. S-PTH concentration was above the upper reference limit $(>65 \mathrm{ng} / \mathrm{l})$ in two participants and below 
Table 2 Basic characteristics of the study participants: healthy, premenopausal, Finnish women aged $31-43$ years ( $n$ 147)

\begin{tabular}{lcc}
\hline Variable & Mean & SE \\
\hline Age (years) & 38 & 0.27 \\
Weight $(\mathrm{kg})$ & 64 & 0.85 \\
Height $(\mathrm{cm})$ & 166 & 0.57 \\
BMl $\left(\mathrm{kg} / \mathrm{m}^{2}\right)$ & 23 & 0.28 \\
Habitual dietary energy intake $(\mathrm{MJ} / \mathrm{d})$ & 7.9 & $0 \cdot 19$ \\
Habitual dietary P intake $(\mathrm{mg} / \mathrm{d})$ & 1411 & $32 \cdot 7$ \\
Habitual dietary Ca intake $(\mathrm{mg} / \mathrm{d})$ & 1056 & 33.6 \\
Habitual dietary Ca:P ratio (mg:mg) & 0.74 & 0.01 \\
\hline
\end{tabular}

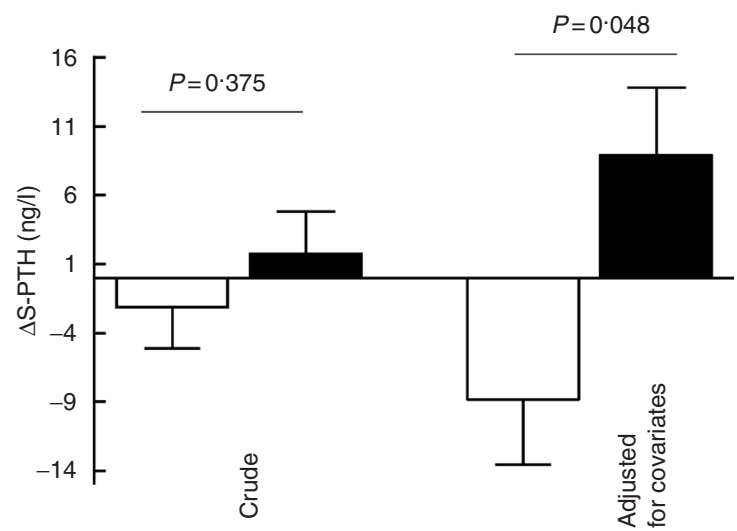

Fig. 1 Effects of total dietary phosphorus on serum parathyroid hormone (S-PTH) concentration in the first ( $\square, n$ 37) and fourth $(\boldsymbol{\square}, n$ 35) quartiles of total $P$ intake among healthy, premenopausal, Finnish women aged $31-43$ years. Values are means with their standard errors represented by vertical bars. Changes in S-PTH $(\Delta \mathrm{S}-\mathrm{PTH})$ values were calculated from the mean S-PTH concentration $(30.6 \mathrm{ng} / \mathrm{l})$. The original mean S-PTH values adjusted for all covariates are presented in the Results section. The covariates used in the model included serum 25-hydroxyvitamin D and serum ionized calcium concentrations, total dietary calcium and sodium intakes, and use of contraceptives. Analysis of covariance was performed

the lower reference limit $(<10 \mathrm{ng} / \mathrm{l})$ in two participants. The mean total $\mathrm{P}$ intake was $961(\mathrm{se} \mathrm{21.9)} \mathrm{mg} / \mathrm{d}$ in the lowest P quartile (first quartile) and 1956 (se 47.8) $\mathrm{mg} / \mathrm{d}$ in the highest quartile (fourth quartile). Relative to the lowest total dietary P quartile, the mean S-PTH concentration was 1.8-fold higher in the highest quartile (S-PTH (ng/l): $21 \cdot 7$ and $39 \cdot 4$ for the lowest and the highest quartile, respectively; $P=0 \cdot 048$, ANCOVA) after adjustments for relevant covariates (Fig. 1).

\section{Effect of phosphate additives on serum paratbyroid bormone}

The mean intake of $\mathrm{P}$ from AP-containing processed cheese among the processed cheese consumers was 240 (sE 34$) \mathrm{mg} / \mathrm{d}$. Compared with non-consumers ( $n$ 110), the mean S-PTH tended to be higher among consumers ( $n$ 37) of processed cheese (S-PTH (ng/1): 29.6 and 33.3 for non-consumers and consumers, respectively). However, the difference was not significant $(P=0 \cdot 190$, ANCOVA)

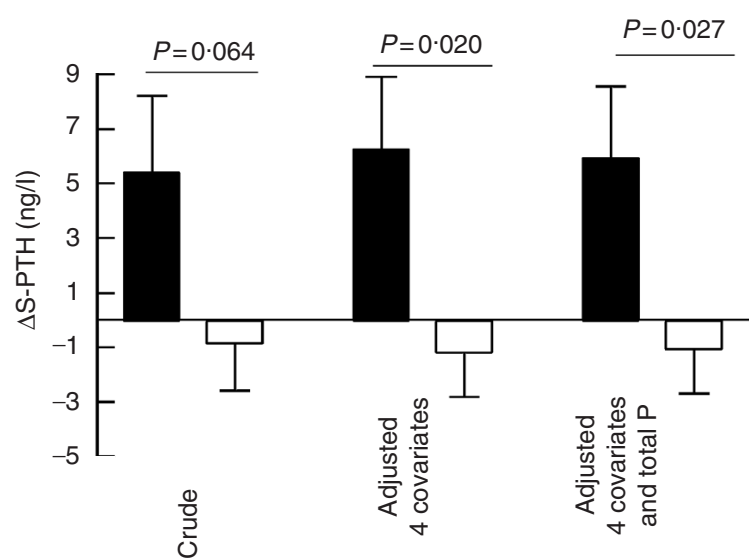

Fig. 2 Effects of processed cheese consumption on serum parathyroid hormone (S-PTH) concentration in the subgroups of consumers (,$n 30$ ) and non-consumers $(\square, n 78)$ of processed cheese, who were not using contraceptives, among healthy, premenopausal, Finnish women aged 31-43 years. Values are means with their standard errors represented by vertical bars. Changes in S-PTH $(\Delta S-P T H)$ values were calculated from the mean S-PTH concentration $(30 \cdot 6 \mathrm{ng} / \mathrm{l})$. The original mean S-PTH values adjusted for all covariates and total dietary phosphorus intake are presented in the Results section. The four covariates used in the model included serum 25-hydroxyvitamin $D$ and serum ionized calcium concentrations, total dietary calcium and sodium intakes. At the final stage, total dietary phosphorus intake was added to the model. Analysis of covariance was performed

probably due to different group sizes and the significant interaction $(P=0 \cdot 023$, ANCOVA) found between processed cheese consumption and use of contraceptives. Due to this interaction, we studied the effects of APcontaining processed cheese on S-PTH in the subgroups of contraceptive users ( $n$ 39) and non-users ( $n$ 108). Among contraceptive non-users, we found that processed cheese consumption was associated with a higher mean S-PTH concentration than non-consumption (S-PTH (ng/1): $36 \cdot 5$ and $29 \cdot 5$ for consumers and non-consumers, respectively) after adjustment for covariates and total $\mathrm{P}$ intake ( $P=0 \cdot 027$, ANCOVA; Fig. 2). Among contraceptive users, mean S-PTH did not differ significantly between consumers and non-consumers of processed cheese after adjusting for four covariates and total $\mathrm{P}$ intake $(P=0 \cdot 153$, ANCOVA).

\section{Effect of natural $P$ on serum paratbyroid bormone}

The mean $\mathrm{P}$ intake $(P<0 \cdot 001$, ANOVA) as well as the mean Ca intake $(P=0 \cdot 009$, ANOVA) from milk and cheese in the higher milk and cheese consumption group ( $n$ 73) was 2.4-fold higher than in the lower milk and cheese consumption group ( $n$ 74). The mean S-PTH concentration was greater with lower than with higher milk and cheese consumption (S-PTH (ng/l): $33 \cdot 2$ and $27 \cdot 8$ for lower and higher consumption, respectively; $P=0 \cdot 065$, ANCOVA) after adjustment for covariates and 


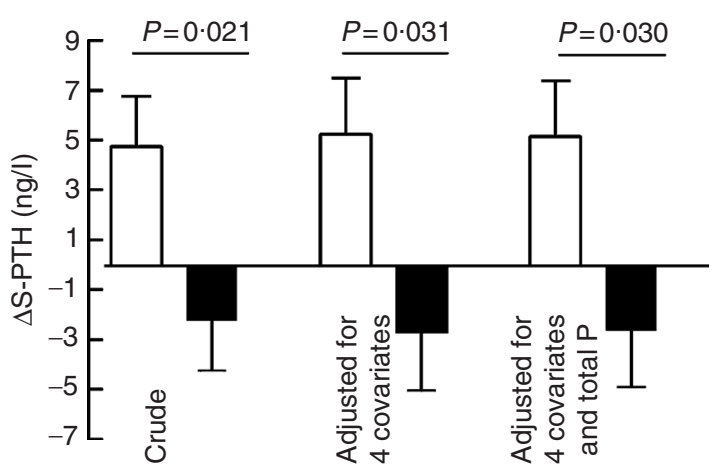

Fig. 3 Effects of milk and cheese, excluding processed cheese, consumption on serum parathyroid hormone (S-PTH) concentration in the subgroups of low $(\square, n 59)$ and high $(\square, n 55)$ milk and cheese consumption, when serum ionized calcium concentration was $<1.225 \mathrm{mmol} / \mathrm{l}$, among healthy, premenopausal, Finnish women aged 31-43 years. Values are means with their standard errors represented by vertical bars. Changes in S-PTH $(\Delta \mathrm{S}-\mathrm{PTH})$ values were calculated from the mean S-PTH concentration $(30.6 \mathrm{ng} / \mathrm{l})$. The original mean S-PTH values adjusted for all covariates and total dietary phosphorus intake are presented in the Results section. The four covariates used in the model included serum 25-hydroxyvitamin D, total dietary calcium and sodium intakes, and use of contraceptives. At the final stage, total dietary phosphorus intake was added to the model. Analysis of covariance was performed

total P intake. As a significant interaction between S-iCa concentration and consumption of milk and cheese ( $P=0.009$, ANCOVA) was found, we examined the effects of milk and cheese on S-PTH concentration in the subgroups of S-iCa $<1 \cdot 225 \mathrm{mmol} / 1$ ( $n$ 114) and S-iCa $\geq$ $1 \cdot 225 \mathrm{mmol} / 1$ ( $n$ 33). S-iCa $=1 \cdot 225 \mathrm{mmol} / 1$ was the point at which the curves for the milk and cheese consumption groups intersected. With lower milk and cheese consumption, when S-iCa concentration was below $1.225 \mathrm{mmol} / \mathrm{l}$, the mean S-PTH was greater than with higher consumption (S-PTH (ng/l): $35 \cdot 7$ and $28 \cdot 0$ for lower and higher consumption, respectively) even after adjustment for covariates and total $\mathrm{P}$ intake $(P=0 \cdot 030$, ANCOVA; Fig. 3). By contrast, with S-iCa concentration $\geq 1.225 \mathrm{mmol} / \mathrm{l}$, the mean S-PTH concentrations between lower and higher milk and cheese consumption groups did not differ significantly $(P=0 \cdot 364$, ANCOVA) after adjustment for the four covariates and total $\mathrm{P}$ intake.

\section{Effects of total dietary $P$, phosphate additives and natural $P$ on serum ionized Ca}

As shown in Table 3, total dietary $\mathrm{P}$ intake significantly affected S-iCa concentration. Compared with the lowest total dietary $\mathrm{P}$ quartile ( $n$ 38), the mean S-iCa concentration was lower in the highest $\mathrm{P}$ quartile ( $n$ 35; $P=0 \cdot 016$, ANCOVA) after adjustment for all relevant covariates. However, the mean S-iCa concentration did not differ between low and high milk and cheese consumption groups $(P=0 \cdot 7$, ANCOVA) or between consumers and non-consumers of processed cheese $(P=0 \cdot 9$, ANCOVA) after adjustment for all covariates (Table 3 ).
Table 3 Mean serum ionized calcium (S-iCa) concentration according to quartiles and groups of the studied participants: healthy, premenopausal, Finnish women aged $31-43$ years $(n 147)$

\begin{tabular}{llcc}
\hline & \multicolumn{2}{c}{ S-iCa $(\mathrm{mmol} / \mathrm{l})$} & \\
\cline { 2 - 3 } Quartiles and groups & Mean & SE & No. of subjects \\
\hline Total P intake & & & \\
$\quad$ 1st quartile & $1.218 \dagger$ & 0.007 & 37 \\
$\quad$ 4th quartile & 1.188 & 0.008 & 35 \\
Milk and cheese* & & & \\
$\quad$ Low consumption & $1.204 \ddagger$ & 0.003 & 74 \\
$\quad$ High consumption & 1.199 & 0.004 & 73 \\
$\begin{array}{l}\text { Processed cheese } \\
\quad \text { Non-consumers }\end{array}$ & $1.202 \ddagger$ & 0.003 & 110 \\
$\quad$ Consumers & 1.201 & 0.005 & 37 \\
\hline
\end{tabular}

*Two groups of equal size (low and high consumption) according to the median intake of $P$ from milk and cheese, excluding processed cheese $(374 \mathrm{mg} / \mathrm{d})$. tMean value was significantly different $(P<0.05)$ from that of the fourth quartile (analysis of covariance), after adjusting for total dietary $\mathrm{Ca}$ intake, serum parathyroid hormone (S-PTH) and serum 25-hydroxyvitamin D $(\mathrm{S}-25(\mathrm{OH}) \mathrm{D})$ concentrations, and the use of contraceptives.

¥Mean value was not significantly different $(P>0.05)$ from that of the high consumption/consumers group (analysis of covariance), after adjusting for total dietary $\mathrm{Ca}$ and P intakes, S-PTH and S-25(OH)D concentrations, and the use of contraceptives.

\section{Discussion}

We observed unfavourable effects of high total dietary $\mathrm{P}$ intake on markers of Ca metabolism. Higher total habitual dietary $\mathrm{P}$ intake was associated with higher S-PTH and lower S-iCa concentrations even after total dietary Ca intake was equalized. Furthermore, we found that in the habitual diets of healthy individuals, foods containing AP had more harmful effects on Ca metabolism than foods containing NP. These effects were seen as higher S-PTH concentrations among those who consumed AP-containing foods. This difference may be due to the different bioavailability of P from AP and NP sources.

In line with the observations in our controlled short-term studies $^{(12,13)}$, we confirmed in the present cross-sectional study that habitual total dietary $\mathrm{P}$ affects Ca metabolism. As dietary P can affect S-PTH directly ${ }^{(17)}$ or through S-iCa ${ }^{(16)}$, we investigated the effects of dietary $\mathrm{P}$ intake on both variables. We found that the mean S-PTH was almost twofold higher and the mean S-iCa lower among participants whose habitual total $\mathrm{P}$ intake was the highest compared with those whose intake was the lowest. These findings are in accord with earlier intervention studies ${ }^{(10,11)}$. In fact, Calvo et al. ${ }^{(10)}$ reported S-iCa concentrations to decrease in response to higher P $(1660 \mathrm{mg} / \mathrm{d})$ intake only in female participants not in males. Furthermore, in a 4-week intervention study in young men ${ }^{(37)}$, P supplementation did not affect S-PTH, likely because of high dietary Ca intake, thus supporting the vital role of adequate $\mathrm{Ca}$ intake simultaneously with high dietary $\mathrm{P}$ intake. On the other hand, it has been found in earlier studies that effects of $\mathrm{P}$ have been greater in women than men ${ }^{(10)}$ and in older than younger women ${ }^{(38)}$. However, the findings here suggest that habitually higher $\mathrm{P}$ intake has a more negative impact 
than lower P intake on Ca and bone metabolism. The effect of total Ca intake was ruled out, as the effects of higher total $\mathrm{P}$ intake on S-PTH and S-iCa were observable even after total dietary $\mathrm{Ca}$ intake was equalized.

Processed cheeses contain both forms of $\mathrm{P}$ (NP and $\mathrm{AP})$. The lower the fat content in processed cheese, the higher the $\mathrm{P}$ content ${ }^{(32)}$ originating from $\mathrm{AP}^{(26)}$. When $\mathrm{P}$ intake is $775-1860 \mathrm{mg} / \mathrm{d}, 60-80 \%$ of dietary $\mathrm{P}$ is absorbed in the intestine ${ }^{(22)}$. As AP-derived $\mathrm{P}$ is almost completely absorbed, the intake of $\mathrm{P}$ from such a source represents a larger burden in the human body. In the present study, we found that consumers of processed cheese had higher S-PTH concentrations than non-consumers. Our findings might reflect the negative influence of $\mathrm{AP}$ on $\mathrm{Ca}$ and bone metabolism found also in earlier intervention ${ }^{(10,11)}$ and short-term $^{(21)}$ studies. In intervention studies ${ }^{(10,11)}$, diets assembled from common foods, including processed foods with AP, increased S-PTH concentration in young adults. AP-containing foods included processed cheese, instant pudding and cola beverages. In postmenopausal women, cola beverage consumption resulted in higher S-PTH concentration and hypocalcaemia ${ }^{(28)}$. In cola beverages, phosphate additives are present in the form of phosphoric acid $\left(\mathrm{H}_{3} \mathrm{PO}_{4}\right)$, while in other foods different forms of phosphate salts, e.g. Na polyphosphates, are used $^{(26)}$. In our study, the intake of $\mathrm{P}$ from processed cheese was not high when compared with total dietary $\mathrm{P}$ intake. Therefore, these new findings suggest that $\mathrm{P}$ intake, which causes an increase in S-PTH, need not necessarily be high if $\mathrm{P}$ is derived from AP.

While P from AP increased S-PTH, the effects of P from NP from dairy products on S-PTH were contradictory. Milk and cheese (excluding processed cheese) are free of AP, but high in NP. In the present study, those who consumed more milk and cheese had lower mean S-PTH concentrations than those who consumed less. However, this difference did not exist when S-iCa concentration was at least $1.225 \mathrm{mmol} / \mathrm{l}$. The high Ca content of milk and cheese probably explains the effect of higher consumption of these products on S-PTH. High Ca intake hinders the absorption of $\mathrm{P}$ in the intestine ${ }^{(23)}$, and $\mathrm{Ca}$ supplementation has been found to suppress higher S-PTH concentrations induced by high $\mathrm{P}$ intake in healthy females ${ }^{(39)}$. Earlier findings support our results, as in postmenopausal women S-PTH decreased with increasing habitual dietary $\mathrm{Ca}$ intake despite simultaneously increasing habitual dietary $\mathrm{P}$ intake ${ }^{(40)}$. In addition, in healthy young females, consumption of fermented cheese in a short-term controlled diet decreased S-PTH concentrations and even decreased bone resorption ${ }^{(21)}$. The importance of a sufficient dietary Ca:P ratio in bone health is supported by the results of epidemiological ${ }^{(41-43)}$, controlled $^{(39)}$ and intervention studies ${ }^{(11)}$ in man as well as in animals ${ }^{(27,44)}$. However, other factors such as milk protein intake $^{(45)}$ or healthy eating habits may be linked to higher milk and cheese consumption, which might cause the favourable effect observed.
In conclusion, higher habitual total dietary $\mathrm{P}$ intakes were associated with higher mean S-PTH and lower mean $\mathrm{S}$-iCa concentrations. We observed in the habitual diets of a randomly selected subgroup of women that AP might affect bone more negatively than other $\mathrm{P}$ sources, as indicated by higher mean S-PTH concentrations among participants consuming AP-containing foods. The effects of NP from milk and cheese, excluding processed cheese, on S-PTH were the opposite of those of AP-containing foods, probably due to higher Ca content in these foods. This may be important new information as the consumption of processed foods has increased during the last decades, which in turn has increased P intake from AP. The intakes of AP and total $\mathrm{P}$ have been shown to rise due to increasing consumption of fast, snack and convenience foods. High dietary P intake may no longer be a problem only in patients with impaired renal function, affecting also healthy individuals whose diet contains excessive P derived from AP. As the foods we examined represent only one type of NP and AP sources, the effects of other foods, e.g. meat or baked products, might be different because dairy products are the only foodstuffs containing large amounts of both $\mathrm{P}$ and $\mathrm{Ca}$. Intervention studies with a wider selection of AP- and NP-containing foods are needed to confirm the present findings in healthy human subjects.

\section{Acknowledgements}

Sources of funding: The Academy of Finland, the Ministry of Education, the Juho Vainio Foundation, the Finnish Konkordia Fund, the 'Liv och Hälsa' Foundation and the Ella and Georg Ehrnrooth Foundation financially supported this study. Conflict of interest declaration: None. Contribution of the authors: M.U.M.K., M.M.L. and T.A.O. conducted the experimental work and the laboratory analysis in 1998. V.E.K., H.J.R., C.J.E.L-A. and M.U.M.K. designed the study. H.J.R. aided V.E.K. in the conceptualization of the research questions. V.E.K. conducted the data analysis and carried out the statistical analysis under the guidance of H.J.R. H.T.V. and M.M.L. assisted V.E.K. with statistical analysis. V.E.K. prepared the manuscript for publication with the help of H.J.R. H.J.R., C.J.E.L-A., H.T.V. and M.M.L. assisted with manuscript revision. C.J.E.L-A. was the principal investigator of the study. Acknowledgements: We thank all volunteers for their participation.

\section{References}

1. Gregory J, Foster K, Tyler H \& Wiseman M (1990) The Dietary and Nutritional Study of British Adults. London: HMSO.

2. Grimm M, Muller A, Hein G, Funfstuck R \& Jahreis G (2001) High phosphorus intake only slightly affects serum minerals, urinary pyridinium crosslinks and renal function in young women. Eur J Clin Nutr 55, 153-161. 
3. Männistö S, Ovaskainen M-L \& Valsta L (2003) The National FINDIET 2002 Study. Kansanterveyslaitoksen julkaisuja B3/2003. Helsinki: Hakapaino Oy.

4. Gronowska-Senger A \& Kotanska P (2004) Phosphorus intake in Poland in 1994-2000. Rocz Państw Zakł Hig 55, 39 (abstract).

5. Standing Committee on the Scientific Evaluation of Dietary Reference Intakes, Food and Nutrition Board, Institute of Medicine, National Research Council (1997) Dietary Reference Intakes: Calcium, Phosphorus, Magnesium, Vitamin D, and Fluoride. Washington, DC: National Academy Press.

6. Hendrix P, Van Cauwenbergh R, Robberecht HJ \& Deelstra HA (1995) Measurement of the daily dietary calcium and magnesium intake in Belgium, using duplicate portion sampling. Z Lebensm Unters Forsch 201, 213-217.

7. Bryant RJ, Cadogan J \& Weaver CM (1999) The new dietary reference intakes for calcium: implications for osteoporosis. J Am Coll Nutr 18, 5 Suppl., 406S-412S.

8. Lombardi-Boccia G, Aguzzi A, Cappelloni M, Di Lullo G \& Lucarini M (2003) Total-diet study: dietary intakes of macro elements and trace elements in Italy. Br J Nutr 90, $1117-1121$

9. Salamoun MM, Kizirian AS, Tannous RI, Nabulsi MM, Choucair MK, Deeb ME \& El-Hajj Fuleihan GA (2005) Low calcium and vitamin $\mathrm{D}$ intake in healthy children and adolescents and their correlates. Eur J Clin Nutr 59, 177-184.

10. Calvo MS, Kumar R \& Heath H 3rd (1988) Elevated secretion and action of serum parathyroid hormone in young adults consuming high phosphorus, low calcium diets assembled from common foods. J Clin Endocrinol Metab 66, 823-829.

11. Calvo MS, Kumar R \& Heath H 3rd (1990) Persistently elevated parathyroid hormone secretion and action in young women after four weeks of ingesting high phosphorus, low calcium diets. J Clin Endocrinol Metab 70, 1334-1340.

12. Kärkkäinen M \& Lamberg-Allardt C (1996) An acute intake of phosphate increases parathyroid hormone secretion and inhibits bone formation in young women. J Bone Miner Res 11, 1905-1912.

13. Kemi VE, Kärkkäinen MUM \& Lamberg-Allardt CJE (2006) High phosphorus intakes acutely and negatively affect calcium and bone metabolism in a dose-dependent manner in healthy young females. Br J Nutr 96, 545-552.

14. Tam CS, Heersche JNM, Murray TM \& Parson JA (1982) Parathyroid hormone stimulates the bone apposition rate independently of its resorptive action: differential effects of intermittent and continuous administration. Endocrinology 110, 506-512.

15. Schiller PC, Dippolito G, Roos BA \& Howard GA (1999) Anabolic or catabolic responses of MC3T3-E1 osteoblastic cells to parathyroid hormone depend on time and duration of treatment. J Bone Miner Res 14, 1504-1512.

16. Herfarth K, Schmidt-Gayk H, Graf S \& Maier A (1992) Circadian rhythm and pulsatility of parathyroid hormone secretion in man. Clin Endocrinol (Oxf) 37, 511-519.

17. Slatopolsky E, Finch J, Denda M, Ritter C, Zhong M, Dusso A, MacDonald PN \& Brown AJ (1996) Phosphorus restriction prevents parathyroid gland growth. High phosphorus directly stimulates PTH secretion in vitro. J Clin Invest 97, 2534-2540.

18. Miyamoto K, Tatsumi S, Segawa H, Morita K, Nii T, Fujioka A, Kitano M, Inoue Y \& Takeda E (1999) Regulation of PiT1 , a sodium-dependent phosphate co-transporter in rat parathyroid glands. Nephrol Dial Transplant 14, Suppl. 1, S73-S75.

19. Liu CC \& Kalu DN (1990) Human parathyroid hormone(1-34) prevents bone loss and augments bone formation in sexually mature ovariectomized rats. J Bone Miner Res $\mathbf{5}$, 973-982.
20. Hodsman AB, Steer BM, Fraher LJ \& Drost DJ (1991) Bone densitometric and histomorphometric responses to sequential human parathyroid hormone (1-38) and salmon calcitonin in osteoporotic patients. Bone Miner 14, 67-83.

21. Karp HJ, Vaihia KP, Kärkkäinen MUM, Niemistö MJ \& Lamberg-Allardt CJE (2007) Acute effects of different phosphorus sources on calcium and bone metabolism in young women: a whole foods approach. Calcified Tissue Int 80, 251-258.

22. Lemann J Jr \& Favus MJ (2003) Intestinal absorption of calcium, magnesium and phosphate. In Primer of the Metabolic Bone Diseases and Disorders of Mineral Metabolism, 5th ed., pp. 93-97 [MJ Favus, editor], Washington, DC: American Society for Bone and Mineral Research.

23. Nolan CR \& Cunibi WY (2003) Calcium salts in the treatment of hyperphosphatemia in hemodialysis patients. Curr Opin Nephrol Hypertens 12, 373-379.

24. Uribarri J \& Calvo MS (2003) Hidden sources of phosphorus in the typical American diet: does it matter in nephrology? Semin Dial 16, 186-188.

25. Blomberg K \& Penttilä P-L (1999) Supervision of Additives in Finland in 1997 and 1998. Research Note no. 8/1999. Helsinki: National Food Administration.

26. Suurseppä P, Penttilä P-L, Hentonen S \& Niemi E (2001) Phosphate as an Additive in Foodstuffs. Research Report no. 12/2000. Helsinki: National Food Administration.

27. Calvo MS \& Park YK (1996) Changing phosphorus content of the US diet: potential for adverse effects on bone. J Nutr 126, 4 Suppl., 1168S-1180S.

28. Fernando GR, Martha RM \& Evangelina R (1999) Consumption of soft drinks with phosphoric acid as a risk factor for the development of hypocalcemia in postmenopausal women. J Clin Epidemiol 52, 1007-1010.

29. Wyshak G (2000) Teenaged girls, carbonated beverage consumption, and bone fractures. Arch Pediatr Adolesc Med 154, 610-613.

30. Tucker KL, Morita K, Qiao N, Hannan MT, Supples LA \& Kiel DP (2006) Colas, but not other carbonated beverages, are associated with low none mineral density in older women: The Framingham Osteoporosis Study. Am J Clin Nutr 84, 936-942.

31. Lamberg-Allardt CJ, Outila TA, Kärkkäinen MU, Rita HJ \& Valsta LM (2001) Vitamin D deficiency and bone health in healthy adults in Finland: could this be a concern in other parts of Europe? J Bone Miner Res 16, 2066-2073.

32. National Public Health Institute, Nutrition Unit (2006) Fineli $^{(R}$ - Finnish Food Composition Database, Release 6. Helsinki: National Public Health Institute; available at http://www.fineli.fi/

33. Babbie E (2001) The Practice of Social Research, 9th ed. Belmont, CA: Wadsworth Publishing Co.

34. Penttilä $\mathrm{R}$, Lindgren $\mathrm{M}$, Miettinen $\mathrm{O}$, Rita $\mathrm{H}$ \& Hanski $\mathrm{I}$ (2006) Consequences of forest fragmentation for polyporous fungi at two spatial scales. Oikos 114, 225-240.

35. Sah SP, Rita H \& Ilvesniemi H (2006) ${ }^{15} \mathrm{~N}$ natural abundance of foliage and soil across the boreal forests of Finland. Biogeochemistry 80, 307-318.

36. Teegarden D, Legowski P, Gunther CW, McCabe GP, Peacock M \& Lyle RM (2005) Dietary calcium intake protects women consuming oral contraceptives from spine and hip bone loss. J Clin Endocrinol Metab 90, 5127-5133.

37. Whybro A, Jagger H, Barker M \& Eastell R (1998) Phosphate supplementation in young men: lack of effect on calcium homeostasis and bone turnover. Eur J Clin Nutr 52, 29-33.

38. Silverberg SJ, Shane E, de la Cruz L, Segre GV, Clemens TL \& Bilezikian JP (1989) Abnormalities in parathyroid hormone secretion and 1,25-dihydroxyvitamin $\mathrm{D}_{3}$ formation in women with osteoporosis. N Engl J Med 320, 277-281. 
39. Kemi VE, Kärkkäinen MUM, Karp HJ, Laitinen K \& Lamberg-Allardt CJE (2008) Increased calcium intake does not completely counteract the effects of increased phosphorus intake on bone: an acute dose-response study in healthy females. Br J Nutr 99, 832-839.

40. Kärkkäinen M, Outila T \& Lamberg-Allardt C (1998) Habitual dietary calcium intake affects serum parathyroid hormone concentration in postmenopausal women with a normal vitamin D status. Scand J Nutr 42, 104-107.

41. Metz JA, Anderson JJ \& Gallagher PN Jr (1993) Intakes of calcium, phosphorus, and protein, and physical-activity level are related to radial bone mass in young adult women. Am J Clin Nutr 58, 537-542.

42. Teegarden D, Lyle RM, McCabe GP, McCabe LD, Proulx WR, Michon K, Knight AP, Johnston CC \& Weaver CM
(1998) Dietary calcium, protein, and phosphorus are related to bone mineral density and content in young women. Am J Clin Nutr 68, 749-754.

43. Basabe TB, Mena VMC, Faci VM, Aparicio VA, Lopez SAM \& Ortega ARM (2004) The influence of calcium and phosphorus intake on bone mineral density in young women. Arch Latinoam Nutr 54, 203-208.

44. Koshihara M, Katsumata S-I, Uehara M \& Suzuki K (2005) Effects of dietary phosphorus intake on bone mineralization and calcium absorption in adult female rats. Biosci Biotechnol Biochem 69, 1025-1028.

45. Budek AZ, Hoppe C, Ingstrup H, Michaelsen KF, Bügel S \& Mølgaard C (2007) Dietary protein intake and bone mineral content in adolescents - The Copenhagen Cohort Study. Osteoporosis Int 18, 1661-1667. 